\title{
NUEVAS VÍAS DE RENOVACIÓN DEL POLICIAL. EL CASO DE FRED VARGAS
}

\section{Ascensión RIVAS HERNÁNDEZ}

Universidad de Salamanca

$\mathrm{E}$ 1 policial es un género narrativo en el que un detective, que normalmente es el protagonista de la historia, resuelve un caso de carácter misterioso y criminal. La observación, la fina inteligencia, el ingenio y el razonamiento deductivo son características del investigador y la causa de su éxito en la resolución de los casos. Los datos están al alcance de cualquiera, incluso del lector, pero nadie salvo él es capaz de inferir lógicamente el fin del enigma del análisis de los hechos.

Como es bien sabido, el origen del policial se remonta a Edgar Allan Poe, creador del detective August Dupin en Los crímenes de la calle Morgue (1841), relato en el que utilizó uno de los argumentos clásicos del género, el llamado «misterio del cuarto cerrado» ${ }^{2}$. Poe sirvió de modelo a Arthur Conan Doyle que a mediados del siglo XIX dio vida literaria a Sherlock Holmes y a su compañero el doctor John H. Watson. Con esta pareja, Conan Doyle introdujo un nuevo elemento en el género que le permitió ampliar su óptica. La figura del colega o el ayudante ofrece un punto de vista más personal del detective, con el que colabora aportando las capacidades y la eficacia que a veces le fallan a aquel, e incluso proporciona algunas pistas para ayudar al lector a resolver la intriga. Conan Doyle, además, hace de Watson el biógrafo de Holmes, con lo que consigue para sus relatos la interesante - por parcial y habitualmente cautivada - perspectiva del narrador testigo que se ha convertido en característica de sus obras. Solo más tarde, a partir de la década de los años veinte del pasado siglo, el género se renueva en los Estados Unidos con la irrupción de nuevos ambientes —ahora de los suburbios-, nuevos perfiles de los personajes - empiezan a ser importantes los aspectos personales del detective- y altas dosis de denuncia social. Surge así la llamada «novela negra» ${ }^{2}$ o

\footnotetext{
${ }^{1}$ Se trata de un tema característico del policial en cuyo argumento se plantea la resolución de un crimen que sucede en una habitación donde es imposible entrar o salir. Además del ejemplo de Poe, son muy conocidos El misterio del cuarto amarillo (1907) de Gastón Leroux, El misterio de la mandarina (1934) de Ellery Queen, El hombre hueco (1935) de John Dickson Carr o La habitación cerrada (1972) de Maj Sjöwall y Per Wahlöö. Chesterton también escribió varios cuentos centrados en el enigma del cuarto cerrado: «El jardín secreto», «El hombre invisible», «La forma equívoca», «La actriz y su doble», entre otros.

${ }^{2}$ A lo largo de la historia ha sido frecuente la confusión entre novela policial y novela negra. Jafet Israel Lara (2013: 29) se hace eco de este cierto caos y explica convincentemente la diferencia entre ambos géneros (29-37).
} 
«realismo noir norteamericano» ${ }^{3}$ que, en palabras de Giardinelli (1996: 15), se caracteriza «por la dureza del texto y de los personajes, así como por la brutalidad y el descarnado realismo», y cuyos límites espacio temporales ha acotado Javier Coma (1983: 38-40). No en vano, la novela negra surgió en una época especialmente violenta, de cambios sociales y económicos que refleja con fidelidad (Colmeiro, 1994: 211; Martín Cerezo, 2009: 32), según se aprecia en la narrativa de Dashiell Hammett, Raymond Chandler y Ross McDonald. Frente al espacio más pequeño y cerrado del policial, la novela negra se desarrolla en lugares abiertos, fundamentalmente en los bajos fondos de las grandes urbes; se caracteriza por un aumento de la acción; destacan en ella los problemas sociales y de marginalidad, y sus tramas son más realistas y verosímiles.

A pesar de los problemas para definir un género literario o un subgénero, no hay duda de que cualquier aficionado sabe distinguir el de su preferencia y que no tendría dificultades importantes para señalar algunas de sus características, que es lo que he tratado de hacer en las líneas precedentes. En este sentido, y como seguramente les sucede a muchos, defiendo una idea flexible de los géneros y me adhiero al parecer de Austin Warren sobre este problema cuando habla del mismo con amplitud y en términos no absolutos:

El género literario es una «institución», como lo es la Iglesia, la Universidad o el Estado. Existe no como existe un animal, o incluso como un edificio o una capilla, una biblioteca o un Capitolio, sino como existe una institución. Cabe trabajar, expresarse a través de instituciones existentes, crear otras nuevas o seguir adelante en la medida de lo posible sin compartir políticas o rituales; cabe también adherirse a instituciones para luego reformarlas (Wellek y Warren: 1979: 271-272).

En opinión de Warren, pues, el género es una institución lo suficientemente sólida para que el lector sepa en qué consiste, y al mismo tiempo es lo suficientemente abierta para admitir variantes, añadidos e incluso reformas.

La cita de Warren me permite abordar con garantías la narrativa de Fred Vargas (París, 1957) porque, siendo fiel al policial, introduce algunos elementos y transforma otros, lo redefine y le da un carácter peculiar propio. Vargas confiere al género una condición renovada al modo como Paul Van Tieghem (1938) lo concebía en términos absolutos. Para él, se trata de un molde que posee unas características determinadas a las que se ajusta el escritor, que después son adaptadas y perfeccionadas por la experiencia del artista. Es lo que Lázaro Carreter (1976: 116) denomina «interpretación coercitiva» del género, defendida también por Pierre Kohler (1938) y Norman H. Pearson (1940) entre otros, y que sería enunciada de forma coherente por los formalistas rusos. Como señala el propio Lázaro Carreter (1986: 116) sintetizando a Tomasevskij:

Cada uno de estos [se refiere a los géneros] sería un conjunto perceptible de procedimientos constructivos, a los que podrían llamarse rasgos del género. Estos rasgos constituyen un esqueleto estructural que yace bajo las obras concretas de ese género, las cuales pueden poseer rasgos propios, pero siempre subordinados a los dominantes.

\footnotetext{
${ }^{3}$ Curiosamente, el adjetivo «noire» se debe al color de las tapas de la colección policiaca que Marcel Duhamel dirigió para la editorial Gallimard desde 1945. Inicialmente la formaron obras de autores norteamericanos (Hammett, Chandler, McDonald), a las que después se unieron novelas de escritores franceses.
} 
Lo que hace Fred Vargas sobre el policial clásico es recoger esos «rasgos» que lo caracterizan para transformar algunos de ellos, alterar funciones, refundirlas y crear otras nuevas. Así consigue reconstruirlo y darle un aire propio sin que por ello pierda sus señas de identidad.

Dentro de la narrativa de la autora me interesa la serie protagonizada por el comisario Jean Baptiste Adamsberg, que se inició con la publicación en 1991 (2007 en español) de El hombre de los círculos azules, aunque la primera novela en nuestra lengua fue El hombre del revés en 2001 (1999 en francés). A pesar de que ambas son originalísimas y de que en ellas ya se observa la regeneración de Vargas, lo cierto es que los textos de la autora se van sofisticando con el paso del tiempo hasta concluir en sus últimas publicaciones -Bajo los vientos de Neptuno (2004-2006), La tercera virgen (20062008), Un lugar incierto (2008-2010) y El ejército furioso (2011-2011)—, donde la singularidad alcanza cotas extremas gracias a la intervención en dos campos: el de los argumentos y el de los protagonistas.

El policial es un género que ha dado siempre mayor importancia a las tramas que a los personajes porque interesaba más contar los hechos y su sucesión lógica que explicar las peculiaridades de los actores, a excepción, claro está, del detective, que fue mejor caracterizado en la novela negra por razones obvias: él también era, como el resto de los individuos representados, un inadaptado social y sus avatares particulares se convertían en un ejemplo más del inconformismo, la marginación y la rebeldía propios del género. En las novelas del matrimonio sueco formado por Maj Sjöwall y Per Wahlöö, considerados los padres del policial europeo, ya se aprecia un cuidado por ambos aspectos —argumentos y protagonistas- (Rivas Hernández, 2014: 327), tendencia que se intensifica en Fred Vargas. En sus obras, sin excepción, existen varios casos abiertos que se entrecruzan y se vinculan con la acción principal. Estas subtramas a menudo distraen, sirven de descanso del caso nuclear y relajan la tensión creada por la compleja situación criminal. En Bajo los vientos de Neptuno, al lado de la supuesta historia dominante, es decir, del viaje a Canadá de Adamsberg y otros agentes para asistir a prácticas de recogida y análisis de fluidos corporales, al comisario le preocupan otras cosas, como señala el narrador: «las recientes apariciones de Fulgence, del nuevo padre [del hijo de Camille] y de Noëlla le habían alejado bastante de los cartones de sudor y de orina» (Vargas, 2006: 183). Pero también está el antiguo caso del hermano gemelo de Jean Baptiste — Raphaël— al que se recupera ahora tras largos años de ausencia, o la revelación de la teniente Retancourt como diosa polivalente y protectora de Adamsberg, entre otros. La complejidad alcanza el grado sumo en La tercera virgen, tal vez la obra más enrevesada de la autora. En ella se concentran los casos de los ciervos destrozados y descorazonados, la muerte de varias mujeres, un antiguo asunto de Adamsberg con la doctora Ariane Lagarde, el extraño caso del teniente Veyrenc y su pelo de dos colores, la existencia de una Sombra que se dedica a profanar tumbas y la presencia de una Camille apenas entrevista que se acuesta con Veyrenc para desesperación de Adamsberg y que posiblilita la aparición esporádica del pequeño Tom. Lo curioso es que ninguna de estas tramas - y de otras a las que no he aludido - se abandona al azar, 
cosa que no habría sido difícil por lo intrincado de la historia. La autora las va recogiendo y cerrando, y consigue que al final todo encaje, cumpliendo con el placer del juego policiaco en el que la narración concluye de forma sorpresiva y con el restablecimiento del orden original (Martín Escribá y Piquer Vidal, 2006: 23-24).

Una segunda característica de las tramas varguianas, ajena al realismo del policial ortodoxo, es que en todas ellas, también sin excepción, aparecen sucesos sobrenaturales, leyendas, mitos, supersticiones del pasado, quimeras o narraciones vinculadas con lo mágico. Esto permite la entrada de lo fantástico en las novelas y hace dudar al lector de que sea posible una conclusión racional del caso, aunque al final los hechos se explican de forma cabal. El mismo narrador de La tercera virgen lo advierte cuando la trama está más enmarañada: «Todo eso, de hilo tenue a razonamiento improbable, formaba un edificio sin pies ni cabeza, más fabuloso que realista» (Vargas, 2008: 303). Así, y por poner solo algunos ejemplos, aparece un hombre lobo en El hombre del revés, el tridente de Neptuno y el fantasma del juez Fulgence en Bajo los vientos de Neptuno, el espectro de una monja del siglo XVIII en La tercera virgen, vampiros y cazadores de vampiros en Un lugar incierto y un ejército de muertos vivientes en El ejército furioso. Ante ellos se hace evidente que los argumentos a menudo rozan la inverosimilitud en lo que supone una nueva seña de identidad del policial de Vargas. La autora, que lo sabe, advierte de ello a su lector estableciendo con él una especie de juego, como sucede en uno de los diálogos de La tercera virgen cuando Adamsberg señala: «Es verosímil [...]. Pero no es la verdad. A veces ocurre que la mentira es verosímil y no la verdad» (Vargas, 2008: 330). O cuando tras idear una de las situaciones más increíbles de toda su producción — la burla de Adamsberg a los policías quebequeses que huye amarrado por la espalda al cuerpo de Retancourt en una escena imposible-, la misma teniente alude de forma expresa a la verosimilitud desde la ironía del autor implícito: «No podemos permitirnos andar con astucias y fallar. La verosimilitud es nuestra arma» (Vargas, 2008: 288).

Sin abandonar todavía el tema de las tramas, en las novelas de Fred Vargas se suceden las «referencias metahistóricas», es decir, alusiones a argumentos y personajes de otras novelas, de modo que para el lector fiel de la autora «éstas se convierten en estancias familiares en las que se mueven individuos conocidos cuyos tics comprende» (Rivas Hernández, 2013: 165). En otro lugar me he referido a las que se muestran en El ejército furioso (Vargas, 2011: 165-167), y por lo que respecta a La tercera virgen son significativas la mención a la venganza de un viejo asesino, el juez Fulgence de Bajo los vientos de Neptuno; las referencias a la estancia en Quebec de Adamsberg y su equipo de la misma novela; la presencia de Vandoosler el Viejo, que remite a Que se levanten los muertos; la alusión a La Bola, el gato instalado en la comisaría, que apareció en Huye rápido, vete lejos o a la oveja George Sand de El hombre del revés, entre otras muchas.

Pero también hay que señalar que en diferentes obras se alude a las relaciones familiares entre personajes, de nuevo inusuales en el policial. Así, Léo, que aparece en El ejército furioso, es pariente de Robert Binet, que a su vez es amigo de Adamsberg, según se lee en La tercera virgen. Esta relación «facilita la confianza de la anciana hacia el comisario y hace más verosímil [...] la trama de [la 
novela]» (Rivas Hernández, 2013: 167). Pero por encima de todas ellas destaca la constante presencia de Camille, protagonista de El hombre del revés, la mujer en torno a la que se construye el mundo afectivo de Adamsberg y que permite revelar la falta de madurez del comisario y su incompetencia sentimental ${ }^{4}$.

Finalmente, es interesante observar el valor que Vargas otorga a la infancia en sus novelas, en lo que supone no tanto subvertir las normas del policial cuanto configurar un mundo propio. De hecho, un número importante de casos está relacionado con acontecimientos vividos durante la niñez. En Bajo los vientos de Neptuno aparece el juez Fulgence, que atemorizaba a los niños de la aldea, entre ellos Jean-Baptiste y su hermano Raphäel. Y en La tercera virgen se presenta al teniente Veyrenc, que se traslada a la comisaría de París buscando explicaciones a un suceso de su infancia en el que, sin saberlo ninguno de los dos, estuvo implicado Adamsberg. También se relacionan con la infancia de Hippolyte y sus hermanos los sucesos que se narran en El ejército furioso. La evocación de este tiempo permite recuperar el espacio de la aldea o del pueblo en el que los protagonistas adultos viven alejados de la gran urbe, como en un no-tiempo eterno y sin alteración. Frente a la novela negra, que se ambienta en los suburbios de las grandes ciudades ${ }^{5}$, las de la escritora francesa sitúan los hechos en pequeñas localidades donde prevalece la idiosincrasia de su gente, sus costumbres y sus formas de relacionarse. En estas poblaciones donde todo el mundo se conoce, es fácil que afloren los conflictos porque se mantienen latentes durante generaciones. La misma comisaría de Adamsberg es un pequeño microcosmos en el que los agentes se relacionan y han establecido afectos que no siempre consiguen someter. De este modo, frente a la denuncia social propia del género negro, el policial varguiano prefiere las distancias cortas, centradas en el individuo, su naturaleza y los problemas que derivan de ella.

Pero quizá el elemento más significativo de la narrativa de Vargas, y sin duda uno de los que aporta mayor grado de renovación, son los personajes, a los que la autora cuida de forma particular. Destacan sobre todo por su carácter insólito, extravagante y sorprendente, muy alejado del realismo del policial ortodoxo. Si nos centramos en los policías de la brigada, Adamsberg destaca por utilizar la intuición como herramienta de trabajo; Danglard es una enciclopedia viviente y cuida solo de cinco hijos pequeños, el menor de los cuales no es suyo; Veyrenc tiene mechas rojas en el pelo y habla en alejandrinos; Mercadet padece hipersomnia; Froissy es bulímica y Retancourt, por terminar con una

\footnotetext{
${ }^{4}$ El personaje de Camille posibilita la entrada del tema amoroso en las historias y permite observar a Adamsberg en un ámbito más personal. Se aprecia, así, su vulnerabilidad, su torpeza en materia afectiva, su inmadurez y su falta de compromiso. Estas tramas, además, distraen de lo meramente criminal y suponen un argumento transversal en las novelas de la serie.

${ }^{5}$ En los orígenes del género policial, las ciudades habían sido un mero decorado al fondo porque lo que realmente interesaba era la resolución del enigma criminal. Pero a partir de los años veinte del pasado siglo, cuando la novela negra surge en Norteamérica, el espacio urbano se convierte en una parte fundamental de los textos, en un signo más de la denuncia y la crítica social. Como señala Martín Escribá (2009: 44), las narraciones de Hammett, Chandler, Thompson, McCoy, Spillane o Irish reflejan «los suburbios urbanos, las cloacas de la ciudad, las calles oscuras sin salida y los barrios más marginales». El desarrollo de la acción tiene lugar por primera vez en espacios abiertos, importantes para mostrar las desigualdades y la censura de la realidad. Como concluye Martín Escribá, «sin el reflejo de este espacio en un tiempo concreto difícilmente la novela negra podría reflejar esa crítica social implícita exhibida» (42-43).
} 
lista que podría ser más larga, es una diosa y utiliza su energía para conseguir cualquier cosa que se propone. Ante esta enumeración, es evidente que Vargas aparta a sus criaturas de lo real y que lo hace de manera consciente. A todos los singulariza con alguna peculiaridad y los provee de cierta aura mágica que los aproxima a lo inverosímil, aunque resultan perfectamente creíbles en el contexto de sus novelas ${ }^{6}$.

Pero además de los fijos, en cada obra aparecen nuevos personajes extravagantes. En La tercera virgen, por ejemplo, destaca Josette, una anciana hacker que se pasea impunemente por la web cifrada del FBI y de cualquier otra institución pública o privada; o Lucio Velasco, el vecino español de Adamsberg al que todavía le pica el brazo que perdió sesenta y nueve años atrás durante la Guerra Civil. Muchos de ellos, no solo los agentes de policía sino también los amigos del comisario, reaparecen en otras novelas y van configurando un mundo reconocible por el lector fiel y un ambiente que aporta ese aire peculiar a las narraciones de Vargas.

Otra característica de los protagonistas, que choca con su falta de realismo y su inverosimilitud, es su alto grado de humanidad. De hecho, a menudo se ven asaltados por sentimientos nobles o miserables (amor, ternura, deseo, compasión, celos, odio, venganza...) cuya descripción revela la pericia de la escritora y su conocimiento profundo de nuestra condición. Una de las afecciones mejor y más ampliamente representadas es la que provocan los celos. En El ejército furioso se describe la necedad y la torpeza de Danglard, cuya inteligencia queda obnubilada al creer que Veyrenc le ha aventajado en la estima de Adamsberg. La exposición de la mezquindad de Danglard es fundamental en la composición de un personaje que se cree superior en lo intelectual. Por eso, Vargas le obliga a entender que es como todos y que comete errores; y después a pedir perdón y a agradecerle a su mayor rival que le haya salvado la vida ${ }^{7}$. El mismo sentimiento de los celos vertebra las relaciones de los personajes en La tercera virgen. Adamsberg está celoso de Veyrenc porque se acuesta con Camille; Danglard ve a través de los celos la incipiente atracción entre Adamsberg y Retancourt, que también se siente herida al percibir la atracción entre el comisario y la forense Lagard; y Noël siente rivalidad ante Veyrenc, a quien no le ve aptitudes para proteger a Adamsberg.

Continuando con los personajes, además, en el policial estándar no son habituales las tramas familiares. El desarrollo de este tipo de argumento puede aparecer en otros autores pero de forma parcial y con otro interés. En las novelas del Sjöwall y Wahlöö, a los que ya he citado, refleja una relación sentimental inadecuada o en crisis, y lo hace al hilo de la denuncia social o para expresar

\footnotetext{
${ }^{6}$ En este sentido, sigue un planteamiento muy aristotélico del concepto. La verosimilitud es, en efecto, uno de los componentes esenciales de la poesía según la Poética, y de él dependen otros como la ficcionalidad. El filósofo de Estagira valora extraordinariamente la credibilidad de lo que se cuenta, aunque reconoce que la verosimilitud ha de entenderse en su contexto (Aristóteles, 1974: 9, 51b29-32). Si el poeta utiliza convenientemente este recurso, es posible aceptar que dos perros hablen, como sucede en El coloquio de los perros de Cervantes, o que un gato piense y oriente la perspectiva narrativa, como ocurre en As Horas Nuas de Lygia Fagundes Telles.

${ }^{7}$ «Los celos primarios, el deseo agudo de aplastar a Veyrenc no habían dejado un solo resquicio para la menor parcela de dignidad e inteligencia. Puede que esas parcelas hubieran tratado de manifestarse, de decir algo, pero él no había oído nada, no había querido saber nada. Como el peor de los cretinos, ese peor que lleva a la destrucción. Y era aquél a quien había querido humillar quien lo había protegido y que había estado a punto de dejar la vida bajo las ruedas del tren» (Vargas, 2011: 257).
} 
mejor el desencanto y la decepción. En el caso de Vargas, los motivos familiares añaden humanidad a la intriga y la alejan de la asepsia de la investigación. El personaje forma parte de una red afectiva que lo acoge, lo envuelve y lo protege, y esto se une a todas las demás características que marcan la diferencia en sus obras.

Por otra parte, los protagonistas del policial varguiano se ven envueltos con frecuencia en un ambiente mágico, especialmente las mujeres a las que suele presentarse como seres fantásticos y capaces de conseguir cualquier cosa por increíble que parezca. En La tercera virgen, por ejemplo, se dice lo siguiente de Retancourt: «Cuando quiere, [...] es capaz de vivir sin dormir, conducir diez noches seguidas, cruzar África a pie y llegar en avión a Vancouver. Conversión de energía, es mágico» (Vargas, 2008: 126). Pero también aparece envuelta en un halo mágico la figura de Camille cuando la vemos tocar la viola, mientras arregla una tubería o cuando recibe a un Adamsberg ebrio en Bajo los vientos de Neptuno. Y para recalcarlo aún más, en esta novela el autor implícito dice de forma expresa en palabras del comisario: «En estos últimos tiempos, mi vida circula por las manos de unas mujeres mágicas. Se lanzan como una bala y una y otra vez la salvan del abismo» (Vargas, 2006: 366).

Los personajes, además, aunque sean secundarios o tengan un carácter colectivo, están perfectamente caracterizados, lo que redunda en la verosimilitud de las novelas y demuestra el interés de la autora por los motivos no estrictamente policiales. Así se explica, por ejemplo, cómo es la conversación entre los normandos, que en realidad ilustra la forma de ser de los habitantes de esa región francesa: «Taciturnos. Aquí, las frases brotaban con dificultad, prudentes, suspicaces, tanteando el terreno a cada palabra. No se hablaba fuerte, no se abordaban los temas abiertamente. Se daban rodeos, como si plantear un tema sin más hubiera sido tan indelicado como echar sobre la mesa una pieza de carnicería» (Vargas, 2008: 68).

Finalmente, en las novelas de Fred Vargas hay una importante carga poético-estética, como ya he señalado para El ejército furioso (Rivas Hernández, 2013: 167-168). Lejos de utilizar un estilo frío y objetivo con el que se cuentan los hechos de forma imparcial y eficaz, la autora utiliza fórmulas subjetivas y constantemente transmite emociones por medio de lo que cuenta. En su caso, no se trata de narrar desde la neutralidad porque no le interesa poner el acento en la crítica o en la carga social, sino de crear un microcosmos en el que priman las peculiaridades — de los individuos, de las situaciones, de los lugares, de los momentos- y de hacerlo desde lo subjetivo y lo afectivo. El tono poético es profuso en las descripciones de afectos o sensaciones donde se utilizan formas comparativas y simbólicas, aunque el lirismo puede aparecer en cualquier situación. En el siguiente ejemplo el narrador detalla lo que siente Adamsberg ante la contemplación de la bondad de Sanscartier. El lenguaje, como puede apreciarse, además de resultar muy visual, está muy alejado del canon del policial estándar: «Distinguía aún [Adamsberg], a lo lejos, la cabeza de Sanscartier el Bueno. Le habría gustado tomar una muestra de su bondad, en una caja, para ponerla en un medallón de papel y, luego, en un alvéolo, e inyectárselo más tarde en las biznas de su ADN» (Vargas, 2006: 488).

A modo de conclusión, parece claro que Vargas utiliza el molde del policial clásico —el enigma, el crimen, el detective, la víctima, el culpable y la investigación-, al que añade elementos cualitativos 
Nuevas vías de renovación del policial. El caso de Fred Vargas

—el barroquismo de las tramas, lo mágico, la singularidad de los personajes, la falta de realismo, el juego con la inverosimilitud o el lirismo- para renovar el género sin hacerle perder sus señas de identidad. Lo que consigue es crear obras híbridas — tan propias de este tiempo- y de calidad que interesan por la intriga y por la consecución lógica de los hechos, pero también por unos personajes muy literarios y de impecable factura que se mueven en un mundo extraordinario donde conviven el misterio y la poesía.

\section{Referencias bibliográficas}

ARISTÓTeles (1974): Poética. Ed. V. García Yebra. Madrid, Gredos.

Colmeiro, José F. (1994): La novela policiaca española: teoría e historia crítica. Barcelona, Anthropos.

ComA, Javier (1983): «La novela negra», en Novela Criminal, Cuadernos del Norte, 19, pp. 38-45.

Giardinelli, Mempo (1996): El género negro. Ensayos sobre la literatura policial. México, Universidad Autónoma Metropolitana.

KOHLER, Pierre (1938): «Contribution à une philosophie des genres», Helicon, I, pp. 233-244.

LARA, Jafet Israel (2012): «De la novela enigma al realismo noir norteamericano: la ruptura de la frontera policíaca», en J. SÁNCHEZ ZAPATERO y À. MARTín ESCRIBÁ, eds., El género negro. El fin de la frontera. Santiago de Compostela, Andavira, pp. 29-39.

LÁZARO CARRETER, Fernando (1986): «Sobre el género literario», en Estudios de Poética (La obra en sí). Madrid, Taurus, pp. 113-120.

MADRID, Juan (1989): La novela policiaca. Barcelona, Acervo.

MARTÍn CEREZO, Iván (2009): «Breve urbanización del género policiaco», en À. MARTín EsCRIBÁ y J. SÁNChez ZAPATERO, eds., Geografías en negro. Escenarios del género criminal. Barcelona, Montesinos, pp. 23-39.

MARTÍn EsCRIBÁ, Àlex (2009): «Análisis de un escenario negro: Barcelona como identidad literaria», en À. MARTín EscribÁ y J. SÁnCheZ ZAPATERo, eds., Geografías en negro. Escenarios del género criminal. Barcelona, Montesinos, pp. 41-54.

—_ y PIQUER VIDAL, Adolf (2006): «De la lupa al revólver: la transformación y el lenguaje de un género», en J. SÁNCHEZ ZAPATERO y À. MARTín EsCRIBÁ, eds., Manuscrito criminal. Reflexiones sobre novela y cine negro. Salamanca, Librería Cervantes, pp. 21-31.

RIVAS HERNÁNDEZ, Ascensión (2013): «El ejército furioso de Fred Vargas o la reinvención del género policial», en J. SÁNCHEZZAPATERO y À. MARTín EsCRIBÁ, eds., Historia, memoria y sociedad en el género negro. Literatura, cine, televisión y cómic. Santiago de Compostela, Andavira, pp. 163-170.

(2014): «Roseanna de Maj Sjöwall y Per Wahlöö. Relectura de un clásico», en À. MARTín ESCRIBÁ y J. SÁnChEZ ZAPATERO, eds., La (re)invención del género negro. Santiago de Compostela, Andavira, pp. 325-332. 
282 Tropelías. Revista de Teoría de la Literatura y Literatura Comparada, 25 (2016) Ascensión Rivas Hernández

VAN TIEGHEM, Paul (1938): «La question des genres littéraires», Helicon, I, pp. 95-101.

VARGAS, Fred (2006): Bajo los vientos de Neptuno. Madrid, Siruela. (2008): La tercera virgen. Madrid, Siruela.

(2010): Un lugar incierto. Madrid, Siruela.

(2011): El ejército furioso. Madrid, Siruela.

WELLEK, René, y WARREN, Austin (1979): Teoría Literaria. Madrid, Gredos. 